Session 2655

\title{
University of Michigan ASEE Student Chapter's Efforts to Promote Multiculturalism in Higher Education
}

\author{
Chris Lorenz, Sara Soderstrom, Michael Keinath, and Don Carpenter \\ University of Michigan
}

\begin{abstract}
One of the major missions of the University of Michigan ASEE Student Chapter is to support the increased involvement of underrepresented minority students in higher education. In the recent history, we have used three different approaches to achieve this part of our mission. First, we are active in the recruitment of minority students through participation in the Society of Hispanic Professional Engineers Regional conference, which was held at the University of Michigan. ASEE student members will be participating in an informational panel about applying to and choosing a graduate school. We will also be hosting an informational booth about graduate school during the conference's Career Fair. Secondly, we actively perform service to the University community with our annual Martin Luther King Jr. Event. In the past few years we have organized various events including a seminar on the climate of graduate school for minority students and an outreach program to inner-city middle schools. This year, we plan to again focus on the climate at the College of Engineering. We hope to organize both informational and social events that will welcome all graduate students and encourage understanding of various cultures. Finally, our student chapter and the College of Engineering will co-host a seminar and workshop focused on issues of diversity and multiculturalism in the classroom. This will help to raise the conscience level to these issues and in turn lead to continual improvement of the classroom climate at our University. These events are all consistent with our mission of supporting the increased involvement of minority students in higher education. They also provide supportive, informational events for all students within the community.
\end{abstract}

\section{Introduction}

The University of Michigan's Student Chapter of American Society for Engineering Education (ASEE) is an organization committed to furthering education in engineering. As part of this mission, our student chapter supports the increased involvement of underrepresented minorities in higher education. In order to accomplish this portion of our mission, we have focused our efforts on organizing events that will complement the College of Engineering's existing recruiting and retention programs.

The rest of this paper will discuss the events that we have organized over the past two years. First, we will outline the events that have been used to inform students about the general undergraduate and graduate engineering programs. Next, the programs designed to continue to improve the educational climate for the minority students within the College of Engineering will be discussed.

"Proceedings of the 2001 American Society for Engineering Education Annual Conference \& Exposition Copyright 2001, American Society for Engineering Education" 


\section{Recruiting efforts}

We have designed outreach programs to the community and to the minority student groups within the College that are focused on informing students about undergraduate and graduate engineering programs. We visited middle schools in urban areas surrounding Ann Arbor, where we were able to address $7^{\text {th }}$ and $8^{\text {th }}$ grade students, and to generate interest in science and engineering related areas of study. At these middle schools, we conducted a small science fair, which included experiments, and hands-on demonstrations that displayed scientific and engineering related principles. Using these demonstrations, we explained such things as lift on an airplane wing, erosion, and the cause of tornadoes. These demonstrations initiated discussions about engineering as an area of study with the students who may not have considered it otherwise. By working with students in the $7^{\text {th }}$ and $8^{\text {th }}$ grades, students that are interested in engineering will have the opportunity to take the appropriate prerequisite math and science classes in high school so that they are better prepared for the undergraduate engineering curriculum.

Every year we sponsor panel discussions, which are aimed at helping students with the different stages of the graduate school application process. In the fall term, departmental graduate admission chairs share advice on writing personal statements and asking for letters of recommendation. Then early in the winter term, we have new graduate students share with the undergraduates what to do before campus visits and what questions to ask while on the visit. These events are well received by the undergraduate students and they are effective for students, who have already decided to attend graduate school. However, minority students make up a lower percentage of graduate student body than undergraduate (at University of Michigan, $8 \%$ minorities in graduate program compared to approximately $13 \%$ in undergraduate program), so we decided to develop programs that are targeted at recruiting minority students to graduate school.

This year we participated in the Society of Hispanic Professional Engineers regional conference, which was held at the University of Michigan. There were about 100 undergraduate students from six different states in attendance at the conference. Members of ASEE volunteered to sit on a panel of graduate students that shared their experiences with the students in attendance. At the conference's career fair, we hosted a table where we answered a variety of questions about graduate school and also did recruiting for the University of Michigan's engineering graduate schools.

These outreach programs allow for us to share our knowledge about the engineering course of study with a larger number of students. More importantly it allows the members of ASEE who participate in the events to see some of the hurdles that need to be overcome in order to achieve an increased participation of minorities in higher education. Working with underrepresented minority student societies within the College opens avenues of discussion about the concerns that students have with the education that they are receiving as well as why more undergraduate students are not interested in graduate school.

"Proceedings of the 2001 American Society for Engineering Education Annual Conference \& Exposition Copyright 2001, American Society for Engineering Education" 


\section{Retention efforts}

From the discussions with minority students, we have found that many are concerned about the educational environment for minorities within the College. As a result, the ASEE student chapter has organized several events that have focused on improving the climate for students. We have invited the entire university to participate in these events, which have included panel discussions, a seminar, and a cultural fair.

In celebration of Martin Luther King (MLK) Day January 1999, ASEE hosted a campus-wide dialogue centered on the theme, "Implementing the Dream in the Sciences and Engineering." This dialogue was intended to promote a widespread and true understanding of Dr. Martin Luther King's vision and to examine the issues that hinder the increased involvement of minorities in higher education in the sciences and engineering. Stephen Director, Robert J. Vlasic Dean of Engineering, delivered an opening address focusing on the College's commitment to diversity. This was followed by an introductory lecture by Dr. Earl Lewis, professor of Afro-American Studies and Dean of the Horace H. Rackham School of Graduate Studies, on Dr. Martin Luther King, his vision and message, and the university's commitment to implementing Dr. King's dream. Dean Lewis's remarks were fitting segues into a panel discussion focused on better understanding of the measures required to eliminate the impediments that hinder diversity in engineering and the sciences. The panel consisted of faculty, staff, graduate and undergraduate students in engineering and the sciences. Each panelist shared briefly their experiences and perspectives on diversity and then the audience joined in a productive discussion about diversity in the sciences and engineering.

For the 2001 MLK Celebration, we are organizing a forum for students from all different backgrounds to share parts of their native culture and customs with the University of Michigan North Campus community. This campus hosts an incredibly diverse group of students, faculty, staff and families within the Colleges of Engineering, Art and Architecture, Urban Planning, and Music as well as university family housing. We proposed this event in coordination with Society of Minority Engineering Students-Graduate Component (SMES-G) and Black Arts Council. We envision the event to be a series of tables and exhibits from the various cultural groups on North Campus. Groups will receive $\$ 50$ to be used for food and other items that exemplify their culture. The cultural fair will be followed by a talent show sponsored by the College and various student organizations.

During the upcoming semester, ASEE is organizing a panel discussion that will commence a series of seminars regarding climate and environment at the College of Engineering. The panelists will briefly discuss concerns of underrepresented minorities in engineering, women in engineering, students with physical and learning disabilities, or international students (both as students and instructors). This will be followed by an interactive discussion between the panelists and the audience. The goal of this panel is to familiarize students, faculty, and staff at the College of the multiple challenges different students face while attending school. Hopefully, this will lead to added awareness and activity towards improving the climate for every student.

The panel will be followed by detailed seminars focused on specific concerns regarding classroom climate and teaching. Faculty, staff, and GSIs will be strongly encouraged to attend

\footnotetext{
"Proceedings of the 2001 American Society for Engineering Education Annual Conference \& Exposition Copyright 2001, American Society for Engineering Education"
} 
these seminars. The first is a Dean's Seminar featuring Dr. James Anderson. Dr. Anderson is Vice Provost and Dean of Undergraduate Studies and Professor of Counselor Education at North Carolina State. He has presented extensive workshops on topics such as retention issues, the infusion of diversity throughout the curriculum and the institution, and critical thinking for diverse populations. This will be followed by seminars focusing on women in engineering, students with disabilities, and international students.

In addition to climate issues, another major concern for the recruitment and retention of underrepresented minorities in graduate school is the visibility of current minority graduate students. The graduate student instructors (GSI), or teaching assistants, are very visible to undergraduate students; however, few GSIs are minority students. This is due to the small number of minority graduate students and also due to the fact that many underrepresented minorities have outside fellowships, and therefore do not need to serve as GSIs. Thus, other means need to be developed that can allow for more exposure of the minority graduate students so that the undergraduate students can meet and interact with possible mentors, or role models. In the next year, the ASEE Student Chapter will work with other graduate student groups to initiate and facilitate such mentorship possibilities for undergraduate students.

\section{Conclusions}

It has been well documented that the recruitment and retention of underrepresented students of color is an issue for all engineering colleges throughout the country. We believe that the programs that we have discussed here have had a positive impact on the University of Michigan's efforts. The climate-related events had the greatest impact on the College as a whole because students, faculty, and staff from throughout the College and University attended them. However, the outreach projects are useful to us as a student group because it gives us an opportunity to work with underrepresented minority student societies directly and allow for us to get their feedback on educational issues within the College.

\section{SARA SODERSTROM}

Sara Soderstrom is currently a Masters student at the University of Michigan, pursuing degrees in Environmental and Chemical Engineering. She is currently serving as the Vice-President of the ASEE Student Chapter. Sara received her BSE in Chemical Engineering from the University of Michigan in 1999. She will graduate in May 2001 and will begin working at McKinsey and Company in August 2001.

\section{CHRISTIAN LORENZ}

Christian Lorenz is a doctoral student in Chemical Engineering at the University of Michigan. He is currently serving as President of the ASEE Student Chapter. He received his BSE and MSE in Chemical Engineering from the University of Michigan concurrently in 1998. Chris was awarded the ASEE Outstanding Student Instructor Award for excellence in teaching in 1998.

\section{MICHAEL KEINATH}

Michael Keinath is currently pursuing a combined Ph.D. in Environmental and Water Resources Engineering and Chemical Engineering. He served as President of the ASEE Student Chapter during the 1999-2000 academic year. Michael received his B.S. in Chemical Engineering from Stanford University in 1996 and has earned M.S.E. degrees in Environmental Engineering and Chemical Engineering from the University of Michigan. 


\section{DON CARPENTER}

Don Carpenter is a doctoral candidate in Civil and Environmental Engineering at the University of Michigan. He is currently serving as Secretary of the ASEE Student Chapter. Don received his B.S.E. in Civil Engineering from

Purdue University in 1993 and his M.S.E. in Civil Engineering at Oregon State University in 1996. Don has served as an adjunct professor at Lawrence Technological University and at Jackson Community College. 